\title{
Safety and Efficiency of Cervical Disc Arthroplasty in Ambulatory Surgery Centers vs. Hospital Settings
}

\author{
MATTHEW F. GORNET, MD, ${ }^{1}$ GLENN R. BUTTERMANN, MD, MS, FAAOS, ${ }^{2}$ RICHARD WOHNS MD, JD, \\ MBA,${ }^{3}$ JASON BILLINGHURST, MD,${ }^{4}$ DARRELL C. BRETT, MD,${ }^{5}$ RICHARD KUBE, MD,${ }^{6}$ J. RAFE SALES, \\ MD,${ }^{7}$ NICHOLAS J. WILLS, MD,${ }^{8}$ ROSS SHERBAN, MD, ${ }^{9}$ FRANCINE W. SCHRANCK, BSN, ${ }^{10}$ ANNE G. \\ COPAY, $\mathrm{PhD}^{10}$ \\ ${ }^{I}$ The Orthopedic Center of St Louise, St Louis, Missouri, ${ }^{2}$ Midwest Spine \& Brain Institute, Stillwater, Minnesota, ${ }^{3}$ NeoSpine, Puyallup, Washington, ${ }^{4}$ Orthopedic \\ Center of Palm Beach County, Atlantis, Florida, ${ }^{5}$ Northwest Spine Surgery, Portland, Oregon, ${ }^{6}$ Prairie Spine and Pain Institute, Peoria, Illinois, ${ }^{7}$ Northwest Spine \\ \& Laser Center, LLC, Portland, Oregon, ${ }^{8}$ Summit Orthopedics, Eagan, Minnesota, ${ }^{9}$ Sherban Spine Institute, Boynton Beach, Florida, ${ }^{10}$ SPIRITT Research, \\ St Louis, Missouri
}

\begin{abstract}
Background: Outpatient surgery has been shown safe and effective for anterior cervical discectomy and fusion (ACDF), and more recently, for 1-level cervical disc arthroplasty (CDA). The purpose of this analysis is to compare the safety and efficiency of 1-level and 2-level CDA performed in an ambulatory surgery center (ASC) and in a hospital setting.

Methods: The study was a retrospective collection and analysis of data from consecutive CDA patients treated in ASCs compared to a historical control group of patients treated in hospital settings who were classified as outpatient (0 or 1-night stay) or inpatient ( 2 or more nights). Surgery time, blood loss, return to work, adverse events (AEs), and subsequent surgeries were compared.

Results: The sample consisted of 145 ASC patients, 348 hospital outpatients, and 65 hospital inpatients. A greater proportion of 2-level surgeries were performed in hospital than ASC. Surgery times were significantly shorter in ASCs than outpatient or inpatient 1-level (63.6 $\pm 21.6,86.5 \pm 35.8$, and $116.7 \pm 48.4$ minutes, respectively) and 2-level (92.4 $\pm 37.3,126.7 \pm 43.8$, and $140.3 \pm 54.5$ minutes, respectively) surgeries. Estimated blood loss was also significantly less in ASC than outpatient and inpatient 1-level $(18.5 \pm 30.6,43.7 \pm 35.9$, and $85.7 \pm 98.0 \mathrm{~mL}$, respectively) and 2-level $(21.1 \pm 12.3,67.8 \pm 94.9$, and $64.9 \pm 66.1 \mathrm{~mL})$. There were no hospital admissions and no subsequent surgeries among ASC patients. ASC patients had $1 \mathrm{AE}(0.7 \%)$ and hospital patients had $10 \mathrm{AEs}(2.4 \%)$. Working patients returned to work after a similar number of days off, but fewer ASC patients had returned to work by the end of the 90-day period.

Conclusions: Both 1- and 2-level CDA may be performed safely in an ASC. Surgeries in ASCs are of shorter duration and performed with less blood loss without increased AEs.
\end{abstract}

Cervical Spine

Keywords: ambulatory surgery center, outpatient surgery, cervical disc arthroplasty, total disc replacement

\section{INTRODUCTION}

Bolstered by trends toward less invasive surgery, as well as modified anesthetic and pain management techniques, surgical procedures are increasingly performed as outpatient procedures across all surgical fields. ${ }^{1}$ Concomitantly, ambulatory surgery centers (ASCs) have rapidly multiplied in the United States, so that outpatient surgeries are increasingly performed in an ASC. 2,3

Similarly in relatively healthy patients, spine surgery has increasingly been performed in outpatient settings including ASCs since the 1980s., Surgeons have analyzed spinal surgeries performed in patient cohorts ranging in size from less than 100 to over 1000 patients. $^{5-20}$ Furthermore, the comparative safety and effectiveness of spine surgery performed on an outpatient versus inpatient basis have been evaluated for a variety of procedures: lumbar discectomy, ${ }^{21,22}$ lumbar decompression, ${ }^{23,24}$ lumbar interbody fusion, ${ }^{25,26}$ anterior cervical discectomy and fusion (ACDF), ${ }^{27-32}$ and cervical disc arthroplasty (CDA). ${ }^{33}$ The complexity of outpatient spine surgeries has also increased from microdiscectomy and decompression, to single-level fusion and multi-level fusion using an anterior approach.

Evidence of the safety of ACDF as an outpatient procedure has accumulated. ${ }^{34}$ Indeed, surgeons have reported safely performing not only 1-level 
but 2-level ${ }^{14-16,28,30,32}$ and 3-level ACDF. ${ }^{11}$ In contrast, there is little published evidence of the safety of outpatient CDA despite the growing use of $\mathrm{CDA}$ as an alternative treatment to ACDF. Beyond the many published Food and Drug Administration (FDA) Investigational Device Exemption (IDE) studies of CDA, which included but did not separately subanalyze and report outpatient outcomes, only 2 studies, based on small patient samples, supported the safety of outpatient 1-level CDA. ${ }^{33,35}$ Hence, the purpose of this analysis is to compare the safety and efficiency of 1-level and 2level CDA performed in an ASC and hospital settings.

\section{MATERIALS AND METHODS}

\section{Patient Sample}

Surgeons retrospectively reviewed the charts of 213 patients who had undergone cervical arthroplasty at 1 or 2 levels with a specific artificial disc (Mobi-C, Zimmer Biomet, Westminster, Colorado). Consecutive patients who met all the inclusion criteria and none of the exclusion criteria were enrolled in this study. Patients had to be treated at 1 or 2 contiguous levels (C3-C7) for intractable radiculopathy (arm pain and/or a neurological deficit) with or without neck pain, or myelopathy due to a 1- or 2-level abnormality localized to the level of the disc space, and with a diagnosis of at least 1 of the following conditions: herniated nucleus pulposus, spondylosis (defined by the presence of osteophytes), and/or visible loss of disc height compared to adjacent levels. The surgery had to occur in an ASC (defined as a distinct financial entity that operates exclusively to provide outpatient surgical services) at least 6 months prior to enrollment in the study. The patients were treated at 9 ASCs across the United States from August 2013 to December 2015. Each study center received approval from a central institutional review board.

\section{Historical Control}

The study patients were compared to a historical control group composed of the patients from the FDA IDE trials of the same artificial disc (NCT00389597). Patients in the clinical trial suffered from symptomatic degenerative disc disease (DDD) with radiculopathy or myeloradiculopathy at 1 or 2 adjacent levels. The inclusion and exclusion criteria of the IDE trials were similar to the criteria of the ASC cohort. The clinical trial surgeries were performed at 24 clinical sites between April 2006 and March 2008. ${ }^{36,37}$ None of the centers nor surgeons who participated in the FDA trials were part of this ASC study.

\section{Patients Groups}

The historical control hospital patients were further divided into inpatient and outpatient groups, based on the length of hospital stay. Hence, this study compares 3 patient groups:

- $A S C$ : patients who underwent surgery in a distinct administrative and financial facility, operating exclusively for providing outpatient services.

- Hospital Outpatient: patients with 1 night or less stay in a hospital-administrated facility (per the Medicare definition).

- Hospital Inpatient: patients admitted for 2 or more nights of stay in a hospital-administrated facility (per the Medicare definition).

\section{Demographic and Medical Data}

The following information was collected from the patients' medical records: basic demographics (age, height, weight, and gender), work status, and workers' compensation status.

\section{Safety Data}

Adverse events (AEs) and subsequent surgeries were collected from the period after surgery to 90 days' postsurgery, corresponding to the Medicaredefined global period for major procedures. A complication was any adverse effect that was determined to be related or might have been related to the device or the cervical spine surgery. For the purposes of this study, this is defined as an event that caused a life-threatening illness, even if temporary in nature; or resulted in permanent impairment of a body function or permanent damage to a body structure; or necessitated medical or surgical intervention to preclude life-threatening illness, permanent impairment of a body function or permanent damage to a body structure (corresponding to the World Health Organization [WHO] classification of Grades 3 and 4 serious AEs).

Data were collected on secondary surgeries occurring on the day of surgery (admission to the ASC) or at any time during the 90-day period 
Table 1. Demographic characteristics: mean \pm standard deviation or number (percent) of patients. Bold text indicates significance.

\begin{tabular}{|c|c|c|c|c|c|}
\hline & $\mathrm{ASC}, \mathrm{N}=145$ & Hospital Outpatient, $\mathrm{N}=348$ & $P$ Values $^{\mathrm{a}}$ & Hospital Inpatient, $N=65$ & $P$ Values $^{\mathrm{b}}$ \\
\hline Age (range) & $43.9 \pm 9.5$ & $44.1 \pm 8.6$ & .88 & $45.5 \pm 8.6$ & .82 \\
\hline Male $(\%)$ & $60(41.4 \%)$ & $176(50.6 \%)$ & .06 & $27(41.5 \%)$ & .98 \\
\hline BMI $\left(\mathrm{kg} / \mathrm{m}^{2}\right)$ & $28.6 \pm 6.3$ & $27.4 \pm 4.5$ & .20 & $27.9 \pm 4.5$ & .93 \\
\hline Obese $(\mathrm{BMI} \geq 30)$ & $47(32.4 \%)$ & $101(29.0 \%)$ & .45 & $22(33.9 \%)$ & .84 \\
\hline Worker's compensation & $29(20.0 \%)$ & $11(3.2 \%)$ & $<.0001$ & $8(12.3 \%)$ & .18 \\
\hline Preoperative work status & & & .73 & & .22 \\
\hline Working & $96(66.2 \%)$ & $232(66.7 \%)$ & & $35(53.9 \%)$ & \\
\hline Unable or not working & $34(23.5 \%)$ & $73(21.0 \%)$ & & $20(30.8 \%)$ & \\
\hline Retired/full time student & $15(10.3 \%)$ & $43(12.4 \%)$ & & $10(15.4 \%)$ & \\
\hline
\end{tabular}

Abbreviations: ASC, ambulatory surgery center; BMI, body mass index.

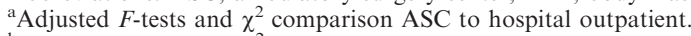

${ }^{b}$ Adjusted $F$-tests and $\chi^{2}$ comparison ASC to hospital inpatient.

postsurgery. Secondary surgeries are defined as any additional operation of the cervical spine. Data collected included the diagnosis, treatment, relation to index surgery, and the relation to the device. Additional information collected for subsequent surgeries included level(s) involved and type of surgery performed. Hospital admissions and emergency room visits were noted in the ASC group only.

\section{Surgical Data}

The following surgical data were collected: number of devices implanted, level of surgery, surgical time, and estimated blood loss. Anesthesia time was recorded for the ASC group only.

\section{Return-to-Work Data}

In the 90 days postsurgery, the number of patients who returned to work and the number of days of missed work were collected on patients who were working at the time of surgery.

\section{Statistical Methods}

The study was designed to test the noninferiority of ASC outcomes versus the historical controls in a hospital setting. The sample size calculation used an assumption of a $2 \%$ rate of complications for the ASC patients, ${ }^{16,29,30}$ and a $4.3 \%$ rate of complications for hospital patients from the results of the Mobi-C IDE trial. Assuming a 1:3 sampling proportion with $80 \%$ power, $\alpha=0.05$, and a minimum clinically significant difference of $3.5 \%$, the minimum number of subjects needed was 440 (ASC, 110; hospital, 330).

Continuous variables were compared with ANOVA and categorical variables with $\chi^{2}$. Due to the small number of AEs and secondary surgeries,
Clopper-Pearson Exact binomial confidence intervals were calculated for each group. Statistical tests were 2 -sided and $P$ values $\leq .05$ were considered significant. Statistical analyses were performed with SAS (version 9.4, SAS Institute, Inc, Cary, North Carolina).

\section{RESULTS}

A total of 145 patients were treated in ASCs. Of the 413 historical controls, 348 were outpatients and 65 inpatients. Table 1 reports the demographic and baseline characteristics of the 3 groups. The ASC group had more workers' compensation patients than the hospital groups. The 3 groups were similar in all other demographic characteristics. A greater proportion of 2-level surgeries were performed in the hospital groups than the ASC group (Table 2). For that reason, the efficiency, safety, and return-towork analyses are reported separately for 1- and 2level surgeries.

In the 90-day period after surgery, only 1 deviceor surgery-related AE was reported in the ASC group $(0.7 \%)$, compared to 10 events reported in the hospital cohort (2.4\%). The overall rate of AEs was $2.0 \%(7 / 348)$ for hospital outpatients and 4.6\% (3/ $65)$ for hospital inpatients. These AE rates are lower than those assumed for the sample size calculations. Therefore, we applied a more conservative noninferiority margin to compare the ASC group to the hospital group. Using a noninferiority margin of $2 \%$, the ASC group was noninferior to all hospital patients and to each hospital subgroup $(P<.05)$. Due to the greater proportion of 2-level surgeries performed in the hospital group, further comparisons of AEs are reported separately for 1- and 2level surgeries (Table 3).

The $1 \mathrm{AE}$ reported in an ASC patient was a wound dehiscence. The wound dehiscence was superficial and treated in an emergency room but 
Table 2. Surgical procedures: number (percent) of patients. Bold text indicates significance.

\begin{tabular}{|c|c|c|c|c|c|}
\hline & ASC & Hospital Outpatient & $P$ Values ${ }^{\mathrm{a}}$ & Hospital Inpatient & $P$ Values ${ }^{\mathrm{b}}$ \\
\hline \multicolumn{6}{|l|}{ Procedure } \\
\hline 1-level & $99(68.3 \%)$ & $160(46 \%)$ & $<.0001$ & $19(29.2 \%)$ & $<.0001$ \\
\hline 2-level & $46(31.7 \%)$ & $188(54 \%)$ & & $46(70.8 \%)$ & \\
\hline \multicolumn{6}{|c|}{ Operated segments } \\
\hline $\mathrm{C} 3-\mathrm{C} 4$ & $2(2.0 \%)$ & $1(0.6 \%)$ & .73 & $0(0 \%)$ & .24 \\
\hline $\mathrm{C} 4-\mathrm{C} 5$ & $8(8.1 \%)$ & $11(6.9 \%)$ & & $0(0 \%)$ & \\
\hline C5-C6 & $50(50.5 \%)$ & $86(53.8 \%)$ & & $14(73.7 \%)$ & \\
\hline C6-C7 & $39(39.4 \%)$ & $62(38.8 \%)$ & & $5(26.3 \%)$ & \\
\hline $\mathrm{C} 3-\mathrm{C} 5$ & $1(2.2 \%)$ & $1(0.5 \%)$ & .46 & $0(0 \%)$ & .59 \\
\hline C4-C6 & $10(21.7 \%)$ & $50(26.6 \%)$ & & $11(23.9 \%)$ & \\
\hline $\mathrm{C} 5-\mathrm{C} 7$ & $35(76.1 \%)$ & $137(72.9 \%)$ & & $35(76.1 \%)$ & \\
\hline
\end{tabular}

Abbreviation: ASC, ambulatory surgery center.

${ }^{a} \chi^{2}$ comparison ASC to hospital outpatient.

${ }^{\mathrm{b}} \chi^{2}$ comparison ASC to hospital inpatient.

did not require surgery. Altogether, the ASC patients experienced $1(0.7 \%)$ AE, 1 (0.7\%) emergency room visit, no hospital readmission and no secondary surgery. The AEs reported in hospital patients (1-level [1] and 2-level [9]) were as follows: neck and/or arm pain (5), dysphagia (2), hematoma (2), and incorrectly placed device (1). Four hospital patients required a secondary surgery: 2 hematoma drainage, 1 laminectomy for radiculopathy, and 1 disc replacement to correct position.

Average surgical times (Table 4) were significantly shorter in ASCs than hospital outpatient and hospital inpatient times for both 1-level (63.6 vs. 86.5 vs. 116.7 minutes for ASC, outpatient, and inpatient, respectively) and 2-level (92.4 vs. 126.7 vs. 140.3 minutes, respectively). Similarly, estimated blood loss was significantly lower in the ASC than the 2 hospital groups for both 1-level (18.5 vs. 43.7 vs. $85.7 \mathrm{~mL}$ ) and 2-level (21.1 vs. 67.8 vs. $64.9 \mathrm{~mL}$ ) procedures. Anesthesia times (recorded in the ASC group only) were $110.1 \pm 39.3$ for 1 -level CDA and $139.6 \pm 53.9$ for 2-level CDA.

Working patients returned to work after a similar number of days off work. However, a greater proportion of ASC patients had not returned to work in the 90-day postoperative period (Table 5). For 1-level CDA, the average numbers of days off work were 28.6, 23.4, and 41.6 (ASC, outpatient and inpatient, respectively). The percentages of 1-level patients who returned to work in the 90-day postoperative period were $47.0 \%, 82.0 \%$, and $80.0 \%$, respectively. For $2-$ level CDA the average numbers of days off were $38.4,24.8$, and 26.4, respectively. The percentage of 2-level patients who returned to work were $66.7 \%, 78.5 \%$, and $72.0 \%$, respectively.

\section{DISCUSSION}

The results of this study confirm the safety and efficiency of 1-level and 2-level CDA performed in the ASC setting. CDA in an ASC had a lower incidence of AEs and secondary surgeries than when performed in hospital. Surgeries in an ASC were of shorter duration and had less blood loss than in the hospital. While other factors may contribute to lower estimated blood loss (EBL) in an ASC, shorter surgery duration was significantly correlated with reduced EBL $(r=0.45 ; P<.001)$.

Past studies reporting on outpatient surgical procedures did not typically distinguish between hospital outpatient departments (HOPDs) and ASCs, so that either 1 or both settings were included in their reports. Indeed, in the only 2 studies of

Table 3. Adverse events and secondary surgeries: number (percent) of patients.

\begin{tabular}{|c|c|c|c|c|c|c|}
\hline & ASC & $95 \% \mathrm{CI}^{\mathrm{a}}$ & Hospital Outpatient & $95 \%$ CI & Hospital Inpatient & $95 \%$ CI \\
\hline 1-level & $\mathrm{N}=99$ & & $\mathrm{~N}=160$ & & $\mathrm{~N}=19$ & \\
\hline Adverse events & $1(1.0 \%)$ & $0.03 \%-5.5 \%$ & $1(0.6 \%)$ & $0.02 \%-3.4 \%$ & $0(0.0 \%)$ & $0 \%-17.6 \%$ \\
\hline Secondary surgeries & $0(0.0 \%)$ & $0 \%-3.7 \%$ & $1(0.6 \%)$ & $0.02 \%-3.4 \%$ & $0(0.0 \%)$ & $0 \%-17.6 \%$ \\
\hline 2-level & $\mathrm{N}=46$ & & $\mathrm{~N}=188$ & & $\mathrm{~N}=46$ & \\
\hline Adverse events & $0(0.0 \%)$ & $0 \%-7.7 \%$ & $6(3.2 \%)$ & $1.2 \%-6.8 \%$ & $3(6.5 \%)$ & $1.4 \%-17.9 \%$ \\
\hline Secondary surgeries & $0(0.0 \%)$ & $0 \%-7.7 \%$ & $2(1.1 \%)$ & $0.1 \%-3.8 \%$ & $1(2.2 \%)$ & $0.06 \%-11.5 \%$ \\
\hline
\end{tabular}

Abbreviations: ASC, ambulatory surgery center; CI, confidence interval.

${ }^{\mathrm{a} C}$ Clopper-Pearson Exact binomial confidence intervals. 
Table 4. Surgical outcomes: mean \pm standard deviation. Bold text indicates significance.

\begin{tabular}{|c|c|c|c|c|c|}
\hline & ASC & Hospital Outpatient & $P$ Values ${ }^{\mathrm{a}}$ & Hospital Inpatient & $P$ Values ${ }^{\mathrm{b}}$ \\
\hline 1-level & $\mathrm{N}=99$ & $\mathrm{~N}=160$ & & $\mathrm{~N}=19$ & \\
\hline Surgery time $(\min )$ & $63.6 \pm 21.6$ & $86.5 \pm 35.8$ & .002 & $116.7 \pm 48.4$ & .037 \\
\hline Estimated blood loss $(\mathrm{mL})$ & $18.5 \pm 30.6$ & $43.7 \pm 35.9$ & .037 & $85.7 \pm 98.0$ & .004 \\
\hline 2-level & $\mathrm{N}=46$ & $\mathrm{~N}=188$ & & $\mathrm{~N}=46$ & \\
\hline Surgery time (min) & $92.4 \pm 37.3$ & $126.7 \pm 43.8$ & $<.0001$ & $140.3 \pm 54.5$ & $<.0001$ \\
\hline Estimated blood loss $(\mathrm{mL})$ & $21.1 \pm 12.3$ & $67.8 \pm 94.9$ & $<.0001$ & $64.9 \pm 66.1$ & .022 \\
\hline
\end{tabular}

Abbreviation: ASC, ambulatory surgery center.

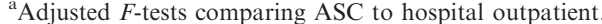

${ }^{\mathrm{b}}$ Adjusted $F$-tests comparing ASC to hospital inpatient.

outpatient CDA, the surgery was performed in HOPDs in 1 study $^{33}$ and ASCs in the other. ${ }^{35}$ However, a difference in the safety of procedures performed in HOPDs and ASCs has been reported. A study compared 175,288 surgical procedures performed on Medicare patients at ASCs and 360,780 at HOPDs. ${ }^{38}$ The following rates per 100,000 procedures were found: 30-day mortality rate (13.5 at outpatient hospital and 8.7 ASC), 30day emergency room visit (365.7 vs. 183.2), and 30day inpatient hospital admissions (548 vs. 165.3). This suggests that procedures were safer when performed in an ASC than an HOPD. Similarly, the current study also observed fewer AEs and secondary surgeries in ASC patients than our hospital outpatient cohort. Patient selection may have impacted the greater safety of CDA in ASCs in our study, given that ASC patients had fewer comorbidities and underwent fewer 2-level procedures than hospital outpatients.

Procedure costs and reimbursement were not analyzed in the present study but financial considerations may have influenced the choice of ASC versus hospital. This study observed a greater proportion of 2-level CDA performed in hospital: reimbursement may have been a factor influencing surgery location.
It should be noted that in the original FDA trial, $84 \%$ of the CDA patients required only a 1-night hospital stay or were discharged the same day as surgery. Hence, the standard for CDA may already be to perform this procedure in an outpatient setting. What this study demonstrates is that performing CDA in an ASC has no greater risk than CDA performed in the hospital. Similar levels of improvement have already been reported for 1and 2-level ACDF in an ASC compared to the hospital. ${ }^{31}$ The surgery and anesthesia times in this study are comparable to those reported in other outpatient cervical surgery studies. ${ }^{15,16,19}$ As in most studies of outpatient cervical surgery, very few patients experienced AEs, needed to be readmitted, or underwent secondary surgery. ${ }^{16,29-31,33}$

More than $90 \%$ of existing ASCs are to some extent owned by physicians and $65 \%$ of ASCs are wholly owned by physicians. ${ }^{39}$ Ownership of an ASC has been called a conflict of interest for surgeons, and is said to influence physician practice patterns and increase their rate of surgical procedures. $^{40,41}$ In an article, concern was expressed regarding the possible underreporting of postoperative morbidity of cervical spine surgery in ASCs $(0.8 \%$ to $6 \%)$, while comparable inpatient cervical procedures reported a morbidity rate of up to $19.3 \%{ }^{42}$ This reported difference in postoperative

Table 5. Return to work: mean \pm standard deviation or number (percent) of patients. Bold text indicates significance.

\begin{tabular}{|c|c|c|c|c|c|}
\hline & $\mathbf{A S C}$ & Hospital Outpatient & $P$ Values $^{\mathrm{a}}$ & Hospital Inpatient & $P$ Values $^{\mathrm{b}}$ \\
\hline 1-level & $\mathrm{N}=99$ & $\mathrm{~N}=160$ & & $\mathrm{~N}=19$ & \\
\hline Working preoperatively ${ }^{c}$ & $66 / 99(66.7 \%)$ & $111 / 160(69.4 \%)$ & .90 & $10 / 19(52.6 \%)$ & .34 \\
\hline Returned to full time work within 90 days & $31 / 66(47.0 \%)$ & $91 / 111(82.0 \%)$ & $<.0001$ & $8 / 10(80.0 \%)$ & .09 \\
\hline Days until returned to full time work & $28.6 \pm 23.2$ & $23.4 \pm 17.3$ & .76 & $41.6 \pm 28.0$ & .51 \\
\hline 2-level & $\mathrm{N}=46$ & $\mathrm{~N}=188$ & & $\mathrm{~N}=46$ & \\
\hline Working preoperatively ${ }^{\mathrm{c}}$ & $30 / 46(65.2 \%)$ & $121 / 188(64.4 \%)$ & .74 & $25 / 46(54.3 \%)$ & .56 \\
\hline Returned to full time work within 90 days & $20 / 30(66.7 \%)$ & $95 / 121(78.5 \%)$ & .17 & $18 / 25(72.0 \%)$ & .77 \\
\hline Days until returned to full time work & $38.4 \pm 23.1$ & $24.8 \pm 18.0$ & .06 & $26.4 \pm 20.4$ & .39 \\
\hline
\end{tabular}

Abbreviation: ASC, ambulatory surgery center.

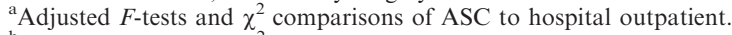

${ }^{\mathrm{b}}$ Adjusted $F$-tests and $\chi^{2}$ comparisons of ASC to hospital inpatient.

${ }^{\mathrm{c}}$ Working full or part time preoperatively. 
morbidity could logically result if surgeons carefully select patients with fewer comorbidities in order to safely perform surgery at an ASC. ${ }^{39}$ Patient selection in this study and choice of procedures (fewer 2-level CDAs) may have positively affected the safety of ASC surgeries.

Factors intrinsic to an ASC have been shown to improve its efficiency independently of financial interests. In this prior study, the efficiency of a hospital inpatient facility was found to be inferior to that of its own ASC. ${ }^{43}$ Orthopedic procedures by the same surgeon were performed more efficiently and more rapidly at the ASC than the inpatient facility. In this reported scenario, both the inpatient and ambulatory facilities were owned and operated by the same hospital without financial incentive to the operating surgeon. Other studies also have found that having dedicated staff and operating rooms improves efficiency and reduces surgical time. ${ }^{44,45}$ Furthermore, infection rates were found to be significantly lower in single specialty ASCs compared to multispecialty ASCs. ${ }^{46}$ Similarly, this study shows that surgical times and estimated blood loss are lower in ASC patients than hospital outpatients, supporting the greater efficiency of ASCs.

While patients in the 3 groups returned to work after a similar number of days, a greater proportion of hospital patients than ASC patients had returned to work by 90 days after surgery for the single-level CDA case. A greater proportion of ASC than hospital patients were workers' compensation cases. Previous studies have shown a delay in return-towork for workers' compensation patients. ${ }^{47}$ The physically demanding nature of the work is assumed to be responsible for the delay in return-to-work, given that the workers' compensation patients are predominantly employed in heavy labor industries. However, in this study, nonworkers' compensation patients returned to work at a much lower rate in ASC surgeries $(59.0 \%)$ than hospital outpatient (93.4\%) and hospital inpatient surgeries (91.2\%). We do not know what factors are responsible for this reported difference, although how this information was collected may have contributed to the difference.

Two key limitations of this study are the use of a historical control and a retrospective chart review. While ASC patients' charts were methodically and thoroughly reviewed, it is possible that patients may not have communicated all pertinent information to their physicians. Additionally, the type and definitions of data collected did not always match between IDE trial patients and the ASC cohort. Hence the number of comparisons between the ASC and hospital cohorts was limited by the availability of comparable data.

Although there are inherent limitations to retrospective studies, the available data support a conclusion of greater efficiency and safety of 1-level and 2-level CDA performed in an ASC compared to hospital settings.

\section{ACKNOWLEDGMENTS}

The authors would like to thank William B. Dolman, MS (Zimmer Biomet) for statistical support and assistance with preparation of the manuscript.

\section{REFERENCES}

1. Baird EO, Egorova NN, McAnany SJ, et al. National trends in outpatient surgical treatment of degenerative cervical spine disease. Global Spine J. 2014;4(3):143-150.

2. Koenig L, Gu Q. Growth of ambulatory surgical centers, surgery volume, and savings to Medicare. Am J Gastroenterol. 2013;108(1):10-15.

3. Hollenbeck BK, Hollingsworth JM, Dunn RL, et al. Ambulatory surgery center market share and rates of outpatient surgery in the elderly. Surg Innov. 2010;17(4):340-345.

4. Gray DT, Deyo RA, Kreuter W, et al. Population-based trends in volumes and rates of ambulatory lumbar spine surgery. Spine (Phila Pa 1976). 2006;31(17):1957-1963; discussion 64 .

5. Rogers LA. Outpatient microsurgical management of ruptured lumbar discs. N C Med J. 1987;48(3):117-120.

6. Zahrawi F. Microlumbar discectomy. Is it safe as an outpatient procedure? Spine (Phila Pa 1976). 1994;19(9):10701074.

7. Tomaras CR, Blacklock JB, Parker WD, et al. Outpatient surgical treatment of cervical radiculopathy. J Neurosurg. 1997;87(1):41-43.

8. An HS, Simpson JM, Stein R. Outpatient laminotomy and discectomy. J Spinal Disord. 1999;12(3):192-196.

9. Asch HL, Lewis PJ, Moreland DB, et al. Prospective multiple outcomes study of outpatient lumbar microdiscectomy: should 75 to $80 \%$ success rates be the norm? J Neurosurg. 2002;96(1 Suppl):34-44.

10. Singhal A, Bernstein M. Outpatient lumbar microdiscectomy: a prospective study in 122 patients. Can J Neurol Sci. 2002;29(3):249-252.

11. Villavicencio AT, Pushchak E, Burneikiene S, et al. The safety of instrumented outpatient anterior cervical discectomy and fusion. Spine J. 2007;7(2):148-153.

12. Garringer SM, Sasso RC. Safety of anterior cervical discectomy and fusion performed as outpatient surgery. $J$ Spinal Disord Tech. 2010;23(7):439-443. 
13. Joseffer SS, Shin P, Wohns RNW. Outpatient anterior cervical discectomy and fusion: indications and clinical experience in a consecutive series of 390 patients. Neurosurg Quarterly. 2010;20(2):107-110.

14. Sheperd CS, Young WF. Instrumented outpatient anterior cervical discectomy and fusion: is it safe? Int Surg. 2012;97(1):86-89.

15. Lied B, Ronning PA, Halvorsen CM, et al. Outpatient anterior cervical discectomy and fusion for cervical disk disease: a prospective consecutive series of 96 patients. Acta Neurol Scand. 2013;127(1):31-37.

16. Tally WC, Tarabadkar S, Kovalenko BV. Safety and feasibility of outpatient ACDF in an ambulatory setting: a retrospective chart review. Int J Spine Surg. 2013;7:e84-e87.

17. Villavicencio AT, Nelson EL, Mason A, et al. Preliminary results on feasibility of outpatient instrumented transforaminal lumbar interbody fusion. J Spinal Disord Tech. 2013;26(6):298-304.

18. Eckman WW, Hester L, McMillen M. Same-day discharge after minimally invasive transforaminal lumbar interbody fusion: a series of 808 cases. Clin Orthop Relat Res. 2014;472(6):1806-1812.

19. Helseth O, Lied B, Halvorsen CM, et al. Outpatient cervical and lumbar spine surgery is feasible and safe: a consecutive single center series of 1449 patients. Neurosurgery. 2015;76(6):728-737; discussion 37-38.

20. Kamson S, Trescot AM, Sampson PD, et al. Fullendoscopic assisted lumbar decompressive surgery performed in an outpatient, ambulatory facility: report of 5 years of complications and risk factors. Pain Physician. 2017;20:E221E231.

21. Best NM, Sasso RC. Success and safety in outpatient microlumbar discectomy. J Spinal Disord Tech. 2006;19(5):334337.

22. Pugely AJ, Martin CT, Gao Y, et al. Outpatient surgery reduces short-term complications in lumbar discectomy: an analysis of 4310 patients from the ACS-NSQIP database. Spine (Phila Pa 1976). 2013;38(3):264-271.

23. Best NM, Sasso RC. Outpatient lumbar spine decompression in 233 patients 65 years of age or older. Spine (Phila $P a$ 1976). 2007;32(10):1135-1139; discussion 40.

24. Miller JW, Sasso RC. Lumbar extraforaminal decompression: a technical note and retrospective study looking at potential complications as an outpatient procedure. $S A S J$. 2011;5(1):4-8.

25. Chin KR, Coombs AV, Seale JA. Feasibility and patientreported outcomes after outpatient single-level instrumented posterior lumbar interbody fusion in a surgery center: preliminary results in 16 patients. Spine (Phila Pa 1976). 2015;40(1):E36-E42.

26. Chin KR, Pencle FJ, Coombs AV, et al. Lateral lumbar interbody fusion in ambulatory surgery centers: patient selection and outcome measures compared with an inhospital cohort. Spine (Phila Pa 1976). 2016;41(8):686-692.

27. Silvers HR, Lewis PJ, Suddaby LS, et al. Day surgery for cervical microdiscectomy: is it safe and effective? J Spinal Disord. 1996;9(4):287-293.

28. Stieber JR, Brown K, Donald GD, et al. Anterior cervical decompression and fusion with plate fixation as an outpatient procedure. Spine J. 2005;5(5):503-507.

29. Liu JT, Briner RP, Friedman JA. Comparison of inpatient vs. outpatient anterior cervical discectomy and fusion: a retrospective case series. BMC Surg. 2009;9:3.

30. Trahan J, Abramova MV, Richter EO, et al. Feasibility of anterior cervical discectomy and fusion as an outpatient procedure. World Neurosurg. 2011;75(1):145-148; discussion 43-44.

31. Adamson T, Godil SS, Mehrlich M, et al. Anterior cervical discectomy and fusion in the outpatient ambulatory surgery setting compared with the inpatient hospital setting: analysis of 1000 consecutive cases. $J$ Neurosurg Spine. 2016;24(6):878-884.

32. Fu MC, Gruskay JA, Samuel AM, et al. Outpatient anterior cervical discectomy and fusion is associated with fewer short-term complications in one-and two-level cases: a propensity-adjusted analysis. Spine (Phila Pa 1976). 2017;42(14):10441049.

33. Wohns R. Safety and cost-effectiveness of outpatient cervical disc arthroplasty. Surg Neurol Int. 2010;1:77.

34. Ban D, Liu Y, Cao T, et al. Safety of outpatient anterior cervical discectomy and fusion: a systematic review and metaanalysis. Eur J Med Res. 2016;21(1):34.

35. Chin KR, Pencle FJR, Seale JA, et al. Clinical outcomes of outpatient cervical total disc replacement compared with outpatient anterior cervical discectomy and fusion. Spine (Phila Pa 1976). 2017;42(10):E567-E574.

36. Hisey MS, Bae HW, Davis RJ, et al. Prospective, randomized comparison of cervical total disk replacement versus anterior cervical fusion: results at 48 months follow-up. $J$ Spinal Disord Tech. 2015;28(4):E237-E243.

37. Radcliff K, Coric D, Albert T. Five-year clinical results of cervical total disc replacement compared with anterior discectomy and fusion for treatment of 2-level symptomatic degenerative disc disease: a prospective, randomized, controlled, multicenter investigational device exemption clinical trial. J Neurosurg Spine. 2016;25(2):213-224.

38. Fleisher LA, Pasternak LR, Herbert R, et al. Inpatient hospital admission and death after outpatient surgery in elderly patients: importance of patient and system characteristics and location of care. Arch Surg. 2004;139(1):67-72.

39. Kurd MF, Schroeder GD, Vaccaro AR. Spine surgery in an ambulatory setting: what can be done safely? JBJS Rev. 2015;3(5). https://doi.org/10.2106/JBJS.RVW.N.00093.

40. Mitchell JM. Do financial incentives linked to ownership of specialty hospitals affect physicians' practice patterns? Med Care. 2008;46(7):732-737.

41. Mitchell JM. Effect of physician ownership of specialty hospitals and ambulatory surgery centers on frequency of use of outpatient orthopedic surgery. Arch Surg. 2010;145(8):732-738.

42. Epstein NE. Cervical spine surgery performed in ambulatory surgical centers: Are patients being put at increased risk? Surg Neurol Int. 2016;7(Suppl 25):S686-S691.

43. Kadhim M, Gans I, Baldwin K, et al. Do surgical times and effectiveness differ between inpatient and ambulatory surgery centers that are both hospital owned? J Pediatr Orthopedics. 2016;36(4):423-428.

44. Small TJ, Gad BV, Klika AK, et al. Dedicated orthopedic operating room unit improves operating room effectiveness. J Arthroplasty. 2013;28(7):1066-1071.e2.

45. Avery DM 3rd, Matullo KS. The effectiveness of a dedicated staff on operating room turnover time in hand surgery. J Hand Surg Am. 2014;39(1):108-110. 
46. Mitchell P, Gottschalk M, Butts G, et al. Surgical site infection: a comparison of multispecialty and single specialty outpatient facilities. J Orthop. 2013;10(3):111-114.

47. Gornet MF, Schranck FW, Copay AG, et al. The effect of workers' compensation status on outcomes of cervical disc arthroplasty: a prospective, comparative, observational study. $J$ Bone Joint Surg Am. 2016;98(2):93-99.

Disclosures and COI: The device manufacturer, Zimmer Biomet (formerly LDR Spine), sponsored the Mobi-C Cervical Disc ASC Study. Zimmer Biomet contributed to the design and conduct of the study, and provided assistance with analysis of data and manuscript review. The authors also report receiving writing or editorial assistance for this paper from Zimmer Biomet. These authors report the following potential or perceived conflicts: M.F. Gornet reports consulting for Aesculap and Medtronic; stockownership of Bonovo, International Spine \& Orthopedic Institute, LLC, Nocimed, OuroBoros, Paradigm Spine; and royalties from
Medtronic and RTI. R. Kube reports research support from Zimmer Biomet and consulting for Paradigm Spine. R. Sherban reports consulting for Zimmer Biomet. N.J. Wills reports consulting for Zimmer Biomet and Medtronic. F.W. Schranck reports stockownership: Nocimed.

Corresponding Author: Matthew F. Gornet, MD, The Orthopedic Center of St Louis, 14825 N. Outer Forty Rd, Suite 200, St Louis, MO 63141. Phone: (314) 324-5482; Email: mfgspine@gmail. com.

Published 15 October 2018

This manuscript is generously published free of charge by ISASS, the International Society for the Advancement of Spine Surgery. Copyright (c) 2018 ISASS. To see more or order reprints or permissions, see http://ijssurgery.com. 